\title{
EDUCAÇÃO ESCOLAR INDÍGENA, INTERCULTURA E HUMBERTO MATURANA: ENTRE CULTURA E SABERES
}

\author{
Valdo Barcelos* \\ Sandra Maders**
}

\begin{abstract}
Resumo
Propomo-nos, neste trabalho, a fazer uma reflexão sobre algumas contribuições de Humberto Maturana que consideramos pertinentes em relação ao descompasso dos processos educacionais em geral e, em particular, em relação à educação escolar indígena. Partimos do pressuposto epistemológico de que a emoção é o sentimento que orienta nossas atitudes cotidianas. A pesquisa se desenvolve tomando como ponto de partida a busca por ampliação do repertório de conhecimentos e saberes que contribuam para o trabalho docente, tanto a partir de sua formação inicial (licenciaturas) quanto continuada. A Biologia do Amor e a Biologia do Conhecimento foram tomadas como princípios para proposições explicativas sobre os fazeres humanos a partir da noção de acoplamento entre biologia e cultura. Constatamos, com esta pesquisa, que as proposições de Humberto Maturana contribuem com importantes e inovadores subsídios para a educação em geral e para a formação de professores(as) na educação escolar indígena em particular; além disso, pode-se afirmar que existe uma proximidade muito significativa entre algumas proposições de Maturana com a cultura Guarani.
\end{abstract}

Palavras-chave: Intercultura. Educação escolar indígena. Humberto Maturana. Emoção.

\footnotetext{
*Doutor em Educação pela Universidade Federal de Santa Catarina (UFSC). Pós-Doutorando [ou "Pós-doutor"] em Antropofagia Cultural Brasileira. Professor Associado IV da Universidade Federal de Santa Maria (UFSM), onde também é professor do Programa de Pós-Graduação em Educação (PPGE). Pesquisador Produtividade1-CNPq. Coordena o Núcleo KITANDA: Educação e Intercultura (CNPq/UFSM). Pesquisador do Núcleo MOVER: Educação Intercultural e Movimentos Sociais da UFSC. E-mail: vbarcelos@terra.com.br.

** Doutoranda em Educação no Programa de Pós-Graduação em Educação (PPGE) da Universidade Federal de Santa Maria (UFSM.) Mestre em educação pelo mesmo Programa. Pedagoga pela Universidade da Região da Campanha (URCAMP). E-mail: sandrinhamaders@hotmail.com.
} 


\section{Introdução}

Concordamos com a necessidade de se buscarem respostas para nossos desafios educacionais nas ciências e nas disciplinas clássicas, bem como no diálogo com outras culturas e na observação dos processos através dos quais elas promovem o "fluir do seu viver" (MATURANA; BLOCH, 1998). Com isso, estaríamos criando espaços de reflexão sobre os contextos sociais e culturais que nos envolvem e agindo nas interfaces de um horizonte intercultural de educação (FLEURI, 1998). Neste trabalho, buscamos essa compreensão e diálogo intercultural no estudo da cultura indígena. Pensamos que a cultura vivida por esse povo tem muito a contribuir para nossa educação, entendimento esse que temos percebido também na leitura de autores que buscam na cultura indígena um respaldo para uma educação na integralidade do ser. Em especial no mundo em que vivemos, no qual, cada vez mais, são frequentes os entrecruzamentos culturais (CANCLINI, 2003), além de encontros e confrontos, agravados pelas relações de poder mundial num contexto de relações interculturais e étnicas (FLEURI, 1998). Pensamos que as proposições teóricas e epistemológicas de Humberto Maturana têm uma relação muito íntima e, portanto, muito a contribuir com esta proposta de formação de professores(as) para o trabalho com educação escolar indígena numa perspectiva intercultural de educação (FLEURI, 2003).

Por exemplo, quando Maturana e Rezepka (2008) colocam que o ser humano é constituído através da linguagem e que tem necessidade contínua de se auto-criar, o autor também afirma que isso faz com que linguagem e cognição, através de ações efetivas, estejam sempre se constituindo socialmente em redes de conversações que configuram nosso mundo. Em algumas comunidades indígenas, todos os processos de aprendizagem se dão à medida que cada criança ou adulto se desenvolve por si só dentro de um conjunto de relações com os outros, sendo autônomos, mas pensando num bem maior. Suas práticas educativas oportunizam a consciência de se ver 
como membro integrante e criador de um todo. Outro aspecto importante a se destacar na educação indígena são os espaços ritualísticos de educação, onde as crianças são educadas a partir de um mundo espiritual e sagrado, dentro de uma relação de confiança e de respeito pelos demais.

$\mathrm{O}$ ato de conhecer, dentro da concepção Guarani, por exemplo, passa pelo percurso do autoconhecimento, de forma que o conhecimento e o ato de conhecer não se separam. O corpo é um mediador na apresentação deste conhecimento: "Corpo nu, corpo vestido, vergonha, emoção, alegria, tristeza, alma, são categorias relevantes na construção na construção do caminho-conhecimento Guarani” (BERGAMASCHI; MENEZES, 2009, p. 72). Os indígenas, dessa maneira, passam a compreender o sentido da cadeia da vida no fluir do viver ou ainda nas coordenações consensuais sobre as quais escreve Maturana: "Um sistema de conversação é portanto, um sistema não linear que não se rege por uma linearidade causa-efeito, mas o efeito rebate sobre a causa criando um sistema fechado que se auto-alimenta" (MATURANA, 1999, p. 37). Observa-se, assim, que, para os indígenas, a questão fundamental, assim como para Maturana, é como as coisas chegaram a ser o que são, e não a sua essência.

Desta maneira, ao propormos dialogar com as teorias de Humberto Maturana e a educação indígena, buscamos mostrar que é possível um diálogo entre os diferentes e que, se este diálogo for pautado pelo respeito e pela amorosidade, as chances de construirmos uma educação mais justa e solidária serão bem maiores. Ao buscar esse diálogo, há que se tomar cuidado para não impor verdades em relação a outras culturas - neste caso, a dos indígenas. No livro Educação Ameríndia, a autora Ana Luiza Teixeira de Menezes descreve esse processo de encontro contraditório com os guaranis como um encontro

De muita satisfação, mas, também, de apreensões. Sentimos hoje que a convivência é alegre, marcada pela aceitação, carinho e amizades que surgiram. Conhecer os guaranis em suas aldeias foi adentrar num universo desconhecido em que a diferença 
se impõe na paisagem, nos cheiros, na língua, nas formas contundentes de dizer que estamos em outro território, cujas relações estão marcadas por muitas incompreensões (MENEZES; BERGAMASCHI, 2009 , p. 29).

Esse olhar ao diferente se dá desde o lugar de onde estamos e somos. Então, essas diferenças que se chocam com a cultura Guarani poderiam parecer, à primeira impressão, um desvio aos nossos "olhos ocidentais" de ver o mundo, ocasionando um desencontro de costumes. Nessa mesma direção, é importante o que sugere Fleuri (1998) ao afirmar que, para além de uma compreensão rígida, disciplinar e normatizadora da diversidade das culturas, emerge o campo híbrido, fluido, polissêmico e, ao mesmo tempo, trágico e promissor da diferença, que se constitui nos entrelugares e nos entreolhares das enunciações de diferentes sujeitos e identidades socioculturais.

\section{Um pouco de história e de legislação}

Acreditamos que uma boa maneira de começar uma discussão - ou um texto -sobre a educação escolar indígena no Brasil é lembrando que, quando aqui chegaram os navegadores portugueses, nos idos de 1500, o território hoje chamado Brasil era habitado por cerca de mil povos diferentes - estes eram os nativos desta terra -, que foram chamados genericamente de "índios" pelos navegadores portugueses.

Se olharmos para nosso passado recente - isto é, os últimos 500 anos -, veremos que cerca de 800 povos desapareceram. Eles foram, de diferentes formas, dizimados, e, com eles, desapareceram suas línguas, seus rituais e seus hábitos alimentares- afinal, quando some uma língua, some com ela uma cultura. Não esqueçamos que esses povos não tinham escritos, mas que sua comunicação era, basicamente, oral. Portanto, quando desaparece um povo com estas características, é aniquilada uma civilização inteira, desaparecendo sua arte e sua filosofia. Sim, sua filosofia, pois essas civilizações possuíam 
um sistema filosófico de vida extremamente complexo e rico em contribuições para as demais formas de pensar a vida no planeta. Tanto isso é verdadeiro que são inúmeros os casos em que pesquisadores de vários países - e mesmo do Brasil - recorrem aos saberes dos povos nativos para os estudarem, copiarem e transformarem em conhecimento científico (e, logo em seguida, em mercadoria) aquilo que é um patrimônio milenar desses povos.

A Lei de Diretrizes e Bases da Educação (LDB, BRASIL, 1996) pode nos mostrar um conjunto de orientações que, mesmo com suas fragilidades, se postas em prática, poderiam proporcionar um avanço significativo nas políticas públicas, no que diz respeito à educação escolar dos povos indígenas. Antes dela, a Constituição Federal, no Capítulo VII, Artigo 231을 previa que:

São reconhecidos aos índios sua organização social, costumes, línguas, crenças e tradições, e os direitos originários sobre as terras que tradicionalmente ocupam, competindo à União demarcá-las, proteger e fazer respeitar todos os seus bens (BRASIL, 1988).

Sobre os direitos legais da história dos povos indígenas e sobre as responsabilidades da União com sua educação, afirma a LDB (BRASIL, 1996):

Os currículos do ensino fundamental e médio devem ter uma base nacional comum, a ser complementada, em cada sistema de ensino e estabelecimento escolar, por uma parte diversificada, exigida pelas características regionais e locais da sociedade, da cultura, da economia e da clientela - O ensino da História do Brasil levará em conta as contribuições das diferentes culturas e etnias para a formação do povo brasileiro, especialmente das matrizes indígenas, africana e européia).

Como se pode constatar, é reconhecido e legitimado que os povos indígenas tenham reconhecidos seus direitos básicos de acesso à educação e, com o respeito e acolhimento 
de suas tradições, crenças, a formas de viabilizar sua existência. Para tanto, o Estado Brasileiro deverá promover, resguardar e responsabilizar-se por:

I - proporcionar aos índios, suas comunidades e povos, a recuperação de suas memórias históricas; a reafirmação de suas identidades étnicas; a valorização de suas línguas e ciências; II - garantir aos índios, suas comunidades e povos, o acesso às informações, conhecimentos técnicos e científicos da sociedade nacional e demais sociedades indígenas e não-índias. Art. 79 - A União apoiará técnica e financeiramente os sistemas de ensino no provimento da educação intercultural às comunidades indígenas, desenvolvendo programas integrados de ensino e pesquisa. $§ \mathbf{1}^{\mathbf{0}-}$ Os programas serão planejados com audiência das comunidades indígenas. $\$ \mathbf{2}^{\mathbf{o}-}$ Os programas a que se refere este artigo, incluídos nos Planos Nacionais de Educação, terão os seguintes objetivos: - fortalecer as práticas sócio-culturais e a língua materna de cada comunidade indígena; - manter programas de formação de pessoal especializado, destinado à educação escolar nas comunidades indígenas; desenvolver currículos e programas específicos, neles incluindo os conteúdos culturais correspondentes às respectivas comunidades; - elaborar e publicar sistematicamente material didático específico e diferenciado (BRASIL, 1996).

Se prestarmos atenção à legislação, poderemos verificar um processo lento, mas que, de alguma forma, tem mostrado resultados, pois o direito a uma educação diferenciada, garantido pela Constituição de 1988, vem sendo regulamentado por meio da legislação subsequente. Além da LDB(BRASIL, 1996) e da Resolução no 3/99 do Conselho Nacional de Educação (BRASIL, 1999), a educação indígena está contemplada no Plano Nacional de Educação (PNE) aprovado em 2001 e no projeto de lei de revisão do Estatuto do Índio.

No Plano Nacional de Educação, são apresentadas considerações gerais sobre a educação escolar indígena, levando-se em conta uma fundamentação histórica, jurídica, 
antropológica e pedagógica que sustenta a proposta de uma escola indígena que seja intercultural, bilíngue e diferenciada. Tal documento foi elaborado através de sugestões de trabalho realizadas por profissionais de diversas áreas do conhecimento, de forma a permitir a construção de um currículo específico e próximo da realidade vivida por cada comunidade indígena, integrando seus etnoconhecimentos com conhecimentos universais selecionados.

A legislação que trata da educação escolar indígena tem apresentado formulações que dão abertura para a construção de uma escola indígena que, inserida no sistema educacional nacional, mantenha atributos particulares como: o uso da língua indígena; a sistematização de conhecimentos e saberes tradicionais; o uso de materiais adequados preparados pelos próprios professores índios; um calendário que se adapte ao ritmo de vida e das atividades cotidianas e rituais; a elaboração de currículos diferenciados; a participação efetiva da comunidade na definição dos objetivos e rumos da escola. A legislação também tem colocado os indígenas e suas comunidades como os principais protagonistas da escola indígena, resguardando a eles o direito de terem seus próprios membros indicados para a função de se tornarem professores a partir de programas específicos de formação e de titulação.

Grande parte dos fundamentos do ensino atual está voltada para uma concepção de formação que prioriza o racional em detrimento do emocional. Os pesquisadores Maturana e Varela (2004) colocam essa questão em debate ao afirmar que o princípio de formação intelectual é emocional e que o amor é um tipo de emoção que funda a própria linhagem biológica do ser humano. Ao falarmos de emoção, remetemo-nos à ideia do domínio de ações que diariamente estamos praticando. As emoções são as disposições específicas para uma ação; as ações são observadas por nós através da linguagem, a qual surge no “estar junto”, na interação com outro e com o meio.

É a emoção a partir da qual se faz ou se recebe um certo fazer que o transforma numa outra ação, ou que o qualifica como um comportamento dessa ou 
daquela classe. Nós humanos existimos na linguagem, e todo o ser e todos os afazeres humanos ocorrem, portanto, no conversar - resultado do entrelaçamento do emocionar com o linguajar. A existência humana faz com que qualquer ocupação humana aconteça como uma rede específica de conversações. Esta é definida em sua especificidade pelo emocionar, que por sua vez define as ações que nela se coordenam (MATURANA; VARELA, 2004, p. 48).

Assim, os autores nos trazem uma nova concepção de linguagem e de emoção que transforma o substantivo em verbo: linguajar, emocionar. A linguagem ocorre, assim, como um conjunto encadeado de ações coordenadas recursivamente e consensualmente. Dentro dessa concepção, não há transmissão de informação, ou seja, o sujeito não recebe a informação de fora, mas cria-a a partir de si mesmo e em congruência operacional com a perturbação (estimulação) do meio em que vive. Nas palavras de Maturana e Rezepka (1998, p. 23), o educar se constitui no processo em que a criança ou o adulto convive com o outro e, ao conviver com este, se transforma espontaneamente, de maneira que seu modo de viver se faz progressivamente mais congruente com o outro no espaço da convivência. Para esse autor, uma criança que cresce no respeito por si mesma pode aprender qualquer coisa e adquirir qualquer habilidade, se o desejar. Esse conviver com o outro, implicando em uma transformação espontânea, existe na medida em que ocorre a aceitação do outro como legítimo em sua diferença, ou seja, a abertura para a alteridade e a abdicação de ações coercitivas. Essa disposição para ações de aceitação ao estranho é um tipo específico de emocionar, denominada por Maturana e Rezepka (1998, p. 22) como "amor". Tal emocionar seria o tipo de disposição para a ação que funda a própria linhagem biológica de nós, seres humanos, no sentido de nos permitir o desenvolvimento das coordenações de ações recursivas consensuais que nos caracterizam como animais "linguajantes" e, com isso, capazes de cooperação e de crescimento em redes de aprendizagem. Para os autores, a Biologia do Amar é o fundamento biológico do mover-se 
de um ser vivo, pois nele há o prazer de se estar onde está, confiante de que se é acolhido, seja pelas circunstâncias, seja por outros seres vivos. É nesse sentido que educar não é apenas transferir conhecimentos e conteúdos, tampouco apenas formalizá-los. Educar é, sim, propor-se uma relação pessoal cooperativa, de abertura ao novo, incentivando quem aprende a partir de um emocionar específico, a emoção da aceitação, que leva à aceitação do outro como legítimo outro.

$\mathrm{Na}$ intenção de ampliar e aprofundar nossas reflexões sobre educação escolar indígena, fazemos também relações com obras de outros autores, como Paulo Freire (1996; 1998; 2008), Fleuri (1998) e Canclini (2003), buscando as relações de formação e tentando, com isso, compreender os fundamentos que sustentam nossas bases de diálogos, isto é, nossas formações em redes de conversações. Propomos, portanto, aumentar e confirmar a necessidade de repertórios de estudos referentes à formação de professores para a educação escolar indígena dentro de uma perspectiva mais humana e mais solidária na aceitação do outro como legítimo outro.

Para tanto, procuramos seguir a linha de raciocínio de Humberto Maturana (1998) ao se referir à conversa na ação educativa, colocando que esta é elemento central na relação que produz o conhecimento. Para ele, "A palavra conversa vem da união de duas raízes latinas, 'cum', que significa 'com', e 'versare', que significa 'dar voltas', de maneira que conversar, em sua origem, significa 'dar voltas com' outro” (MATURANA; REZEPKA, 1998, p. 80). A conversa constitui-se, assim, em um espaço relacional por excelência na ação educativa, de forma que o educar deixa de ser entendido como um ato da fala enquanto apresentação de quem domina certas informações pronunciadas como verdades e passa a se constituir como comunicação de sistemas viventes nas ações comuns. A Biologia do Amor e a Biologia do Conhecimento ${ }^{1}$ foram tomadas como princípios para as proposições explicativas sobre os fazeres humanos, a partir da noção de biologia como processo de acoplamento cultural: "Como vivermos é como educaremos, e conservaremos no viver o
1 Biologia do Amor e Biologia do Conhecimento são denominações que Humberto Maturana apresenta para especificar um espaço de reflexão, o qual é entendido como um domínio do nosso viver que se estabelece nas relações que participamos no conversar, isto é, no entrelaçamento do emocionar e do linguajear. Esse espaço aparece conforme se definem, na linguagem, explicações e distinções sobre a experiência de definir o próprio espaço que se quer definir. Mais recentemente, Maturana e Dávila (2005) estabelecem esses domínios como uma dinâmica relacional para a qual propõem a denominação matriz biológica e cultural da existência humana. 
2 A Biologia da cognição ou Teoria de Santiago originouse do estudo das redes neurais e, desde o início, esteve ligada com a concepção de autopoiese de Maturana (Teoria da Organização da vida, a partir da qual se entendia o Processo de cognição como processo de vida). A cognição, conforme Maturana (ano), é a atividade envolvida na autogeração e na autoperpetuação de redes autopoéticas. Em outras palavras, a cognição é o próprio processo da vida. A teoria da cognição de Santiago recebe esse nome por que foi desenvolvida em Santiago do Chile, país de residência do autor, entre os anos de 1972 e 1980. mundo que vivemos como educandos. E educaremos outros com nosso viver com eles, o mundo que vivermos no conviver" (MATURANA, 1999a, p. 30). A educação, nesse sentido, passa a ser parte essencial da humanização de homens e de mulheres e não uma desintegração de valores ou uma simetria inversa. A educação precisa ajudar o ser humano a cumprir a sua vocação ontológica e, para isso, é necessário que cada um seja ator/autor de sua história. Arroyo (2000, p. 48) contribui, nesse sentido, afirmando que

Os professores devem ser capazes de trabalhar em ambientes escolares que possam tornar-se centros de conhecimento coletivo e de solidariedade. Devem estar preparados para compreender a importância de um discurso democrático e as contradições da diversidade cultural.

É nesse sentido que Maturana (1999a) define a vida como um processo permanente de conhecimento, identificando o viver com o conhecer. Sua teoria da cognição, conhecida também como Biologia da Cognição ou como a Teoria de Santiago, ${ }^{2}$ coloca os seres vivos como co-construtores do mundo, seres em constante processo de aprendizagem, condição essencial para a conservação da vida. Assim, construímos o mundo na interação com o outro, influenciamos e modificamos na mesma medida em que somos, também, modificados e influenciados. É nesse coexistir que percebemos e passamos a conhecer nossa realidade. Outro autor que também traz grande contribuição nesse sentido é Paulo Freire (2008); ele descreve o processo da transformação do indivíduo através da educação dentro de um ambiente de relações de respeito. Em sua perspectiva, transformar, no sentido de que o educando se torne o "verdadeiro sujeito da construção" de seu conhecimento,

Faz parte das condições em que aprender criticamente é possível a pressuposição por parte dos educandos de que o educador já teve ou continua tendo experiência da produção de certos saberes e que estes não podem 
a eles, os educandos, ser simplesmente transferidos

(FREIRE, 2008, p. 26).

A educação só será significativa para os que aprendem quando estes estiverem em um ambiente de respeito, onde se valorize o diálogo e, principalmente, a singularidade de cada um na medida em que, transpondo para educação escolar, "O professor que pensa certo deixa transparecer aos educandos que uma das bonitezas de nossa maneira de estar no mundo e com o mundo, como seres históricos, é a capacidade de, intervindo no mundo, conhecer o mundo" (FREIRE, 2008, p. 28).

\section{Considerações para se pensar}

Este trabalho decorre de uma investigação que tem tido sequência no doutorado em Educação. Como referido anteriormente, ela trata a respeito da formação inicial e continuada de professores em geral e, em particular, para educação escolar indígena, tendo como base algumas obras do pensador chileno Humberto Maturana, referencial teórico sobre o assunto, o qual afirma que não podemos viver sem considerarmos que somos seres da emoção e que é a emoção que coordena o fluir de nosso viver.

Nesta pesquisa, os estudos e as análises sinalizam para uma grande potencialidade na obra de Maturana, no sentido de ampliação do repertório de conhecimentos no que diz respeito à formação de professores numa perspectiva intercultural e que busca valorizar os aspectos relacionados às emoções. No presente momento, as duas proposições iniciais, a Biologia do Amor e a Biologia do Conhecimento, têm sido aprofundadas $\mathrm{e}$, com isso, temos buscado relacionar sua fundamentação com o processo de ensino-aprendizagem escolar a partir de um repensar da formação docente. Percebemos, também, que existe uma proximidade bastante significativa em relação às ideias e às proposições de Maturana e de outros autores e pensadores brasileiros, como, por exemplo, Paulo Freire. Uma vez que seremos e formamos futuros professores, necessitamos 
respeitar e valorizar as diferenças, valorizar o saber que as crianças trazem na sua bagagem cultural, direcionando nossas aulas para um saber fazer que tenha relação com seu cotidiano, com o respeito pelo outro. Para Maturana (1998, p. 29),

O educar se constitui no processo em que a criança ou o adulto convive com o outro e, ao conviver com o outro, se transforma espontaneamente, de maneira que seu modo de viver se faz progressivamente mais congruente com o do outro no espaço da convivência. Não respeitar esses saberes, exigindo que o aluno "saiba" apenas o que o professor "ensinou" gera uma forma de repreensão e condicionamento a que Fleuri (2008, p. 34) chama de "silêncio da mente":

A custa, por exemplo, de ser forçado na escola a repetir sempre o que o professor diz, o estudante acaba sendo tolhido em sua capacidade de pensar com a própria cabeça. E, pior, tenta-se convencê-lo de que o saber "de quem tem competência" é absolutamente verdadeiro e inquestionável.

Nas palavras de Freire (1996, p. 23), “desde os começos do processo de formação, vai ficando cada vez mais claro que, embora diferentes entre si, quem forma se forma e reforma ao formar e quem é formado forma-se e se forma ao ser formado". Pensando dessa maneira, fica claro que a formação dos professores e professoras, tanto inicial quanto continuada, é construída por toda vida. Percebemos também que, mesmo em uma rápida reflexão sobre ideias e conceitos tão complexos, uma das grandes dificuldades, para reestruturarmos nossa maneira de ser e estar no mundo,é,justamente, nossa resistência em reformular a nossa estruturação rígida e dicotômica de pensar e agir predominante no processo educativo até então praticado em nossa cultura - um processo educativo em que a capacidade de aprender ficou reduzida à dimensão de nossa racionalidade, desconsiderando (e, em alguns casos, até mesmo negando) as demais dimensões e potencialidades de nosso organismo bio-psico-antropológico-cultural e social.

Ao ser superestimado o racional, criam-se as condições ecológicas para o desenvolvimento de uma relação, ao fim e 
ao cabo, antissocial. Negamos, com a supremacia da razão, a possibilidade daquilo que nos faz seres humanos: a nossa maneira particular e especial de viver juntos numa conversação que nos faz seres sociais, capazes de criar espaços de coexistência solidária e amorosa através de um linguajar comum. Sem dúvida, pensar uma escola que possa associar os saberes aos fazeres dos povos indígenas e que, ao mesmo tempo, consiga contemplar aquilo que um currículo e uma organização escolar tradicional do mundo ocidental determinam como mínimo a ser considerado para os diferentes níveis de escolarização é um grande desafio pedagógico e epistemológico. Em nosso entendimento, uma das maneiras de enfrentarmos esse desafio e avançarmos é, justamente, buscando interlocuções com ideias e proposições epistemológicas que enfatizem o diálogo intercultural, o cuidado com o outro e a escuta sensível daquilo que perpassa os processos relacionais nas comunidades de aprendizagem. Ao refletir sobre este desafio, Menezes e Bergamaschi (2009, p. 182) assim se manifestam, dando-nos uma pista possível a ser seguida:

É no fazer diário, marcado pela cosmologia indígena, que se faz uma escola diferenciada, nos pequenos, porém potentes indícios que apontem um outro modo de fazer escolar. Nessa perspectiva, os sentidos da escola vão se constituindo em atos ao apropriarem-se de um aparelho educativo que não nasceu no interior de suas antigas tradições, mas que, ao trazê-lo para dentro da aldeia, conferem-lhe significados próprios.

Ao propormos o cuidado e a escuta ${ }^{3}$ como princípios epistemológicos para se pensar uma educação escolar junto às comunidades indígenas, estamos, concretamente, buscando criar um espaço de convivência escolar que possa abrigar não só as diferenças entre a cultura indígena e a cultura ocidental, como também queremos incentivar uma relação de reciprocidade intercultural de aprendizagens comuns. Não podemos esquecer que uma questão fundamental para o acolhimento daqueles(as) que chegam à escola é que estes
3 A palavra escuta aqui utilizada é intencional. Com ela, queremos ressaltar a importância de, mais que ouvirmos o que o outro tem para dizer ou está dizendo, há que se parar para lhe dar atenção. Ou seja, queremos dar à palavra escuta seu sentido de origem, auscultare, dar atenção ao que vem de dentro, dar espaço para a voz do interior, ouvir o e com o coração e não apenas com a razão. 
recebam uma atenção que respeite o fluir de seu viver original. Isso não significa a pura e simples acomodação às diferenças, mas tem a ver com a criação de um espaço onde possam ser mediados os conflitos inter-étnico-culturais tendo como ponto de partida a resolução pacífica dos mesmos. Com isso, estamos sugerindo uma escola que venha ao encontro do sentido que educandos e educandas possam atribuir a ela - sentidos estes que não serão, certamente, em muitos casos, os mesmos que os gestores e professores(as) estão habituados a conferir à escola.

Nessa perspectiva de pensar e organizar um espaço escolar de caráter intercultural, sugerimos levar-se em conta o que sugere Maturana (1999a, p. 13) como um dos papéis fundamentais da escola:

A tarefa da educação escolar é permitir e facilitar o crescimento das crianças como seres humanos que respeitem a si próprios e os outros com consciência social e ecológica, de modo que possam atuar com responsabilidade e liberdade na comunidade a que pertencem.

Para o autor, o conhecimento é uma construção na linguagem, e esta é construída nas relações de afeto e de carinho, que por sua vez, são emocionadas, como já havíamos mencionado anteriormente. Na perspectiva de Maturana (1998), o educar se constitui no processo em que a criança ou o adulto convive com o outro e, ao conviver com o outro, se transforma espontaneamente, de maneira que seu modo de viver se faz progressivamente mais congruente com o outro no espaço da convivência. É em função disso que, para esse autor, uma criança que cresce no respeito por si mesma pode aprender qualquer coisa e adquirir qualquer habilidade, se o desejar. Temos um exemplo disso quando Maturana coloca que os seres humanos são constituídos através da linguagem e têm a necessidade contínua de se auto-criar, o que faz com que linguagem e cognição, através de ações efetivas, estejam sempre se constituindo socialmente em redes de conversações que configuram nosso mundo. 
Também para os indígenas todos os processos de aprendizagem se dão à medida que cada criança ou adulto se desenvolve por si só dentro de um conjunto de relações com os outros, sendo autônomos, mas pensando em um bem maior. Suas práticas educativas oportunizam a consciência de se ver como membro de um todo, integrantes e criadores. Este conviver com o outro, implicando em uma transformação espontânea, existe na medida em que ocorre a aceitação do outro como legítimo em sua diferença, ou seja, na abertura para a alteridade e na abdicação de ações coercitivas. Para Maturana (1999b, p. 30), "Como vivermos é como educaremos, e conservaremos no viver o mundo que vivemos como educandos. E educaremos outros com nosso viver com eles, o mundo que vivermos no conviver".

Assim, percebemos que tanto para os indígenas quanto para Maturana, o educar deixa de ser entendido como um ato da fala que consiste simplesmente na apresentação de quem domina certas informações pronunciadas como verdades e passa a se constituir como comunicação de sistemas viventes nas ações comuns.

\section{Referências}

ARROYO, Miguel G. Ofício de Mestre: imagens e auto-imagens. Petrópolis: Vozes, 2000.

BRASIL. Constituição (1988). Constituição da República Federativa do Brasil, Brasília, DF: Senado Federal, 1988.

Lei no 9.394, de 20 de dezembro de 1996. Estabelece as diretrizes e bases da educação nacional 1996. Disponível em: <https://www.planalto.gov.br/ccivil_03/Leis/L9394.htm〉. Acesso em: 22 out. 2015.

. Resolução CEB no 3, de 10 de novembro de 1999. Fixa Diretrizes Nacionais para o funcionamento das escolas indígenas e dá outras providências. 1999. Disponível em: <http://portal.mec. gov.br/cne/arquivos/pdf/CEB0399.pdf>. Acesso em: 22 out. 2015.

CANCLINI. N. G. Culturas híbridas. São Paulo: EDUSP, 2003.

FLEURI, R. M. Intercultura e movimentos sociais. Florianópolis: NUP/UFSC, 1998. 
. Intercultura e educação. Revista Brasileira de Educação, Campinas, SP, n. 23, 2003.

. Entre disciplina e rebeldia na escola. Brasília: Liberlivro, 2008.v.1.p. 124.

FREIRE, P. Pedagogia da autonomia. Rio de Janeiro: Paz e Terra, 2008.

. Educação como prática de liberdade. 22. ed. Rio de Janeiro: Paz e Terra, 1996.

. Emoções e linguagem na educação e na política. Belo Horizonte: UFMG, 1998.

MATURANA, H. R. Emoções e linguagem na educação e na política. Belo Horizonte: Editora UFMG, 1999a.

. Transformacion em la convivência. Santiago do Chile: Dolen Ediciones, 1999b.

MATURANA, H. R.; BLOCH,S. Biologia del emocionar y alba emoting. Santiago do Chile: Dilmen, 1998.

MATURANA, H. R.; DÁVILA, X. P. Y. Ética e desenvolvimento sustentável: caminhos para a construção de uma nova sociedade. Revista Psicologia \& Sociedade, Porto Alegre, v. 16, n. 3, p. 102110, 2005.

MATURANA, H. R.; REZEPKA. S. Formação e capacitação. Tradução de: Jiame S. Clossen. Rio de Janeiro: Vozes, 2008.

MATURANA, H. R.; VARELA, F. A árvore do conhecimento: as bases biológicas do conhecimento humano. Tradução de: Humberto Mariotti e Lia Diskin. Campinas, SP: Ed. Psy, 1995. São Paulo: Ed. Palas Athena, 2004.

MENEZES, M. A.; BERGAMASCHI, M. A. Educação ameríndia: a dança e a escola Guarani. Santa Cruz do Sul: Edunisc, 2009.

Submetido em: $18 / 11 / 2016$

Aprovado em: 14/12/2016 


\title{
INDIGENOUS SCHOOL EDUCATION, INTERCULTURE AND HUMBERTO MATURANA: BETWEEN CULTURE AND KNOWLEDGE.
}

\begin{abstract}
We propose to make a reflection about some of Humberto Maturana's contributions that we consider relevant related to the mismatch of educational processes in general, and in Indigenous Education in particular. We start from the epistemological assumption that the emotion is the feeling that guides our everyday attitudes. The research is developed taking as starting point the search for enlargement of the repertory of knowledge and learning that contributes to the instructors work, since their initial formation (degrees) to their continuing education. The Biology of Love and Biology of Knowledge were taken as principles for the explaining propositions about the human doings, starting from the notion of coupling between biology and culture. We found in this research that (1) the Humberto Maturana's propositions contribute with important and innovative subsidies to the education in general and to teacher's formations in indigenous education in particular and (2) that there is a very significant proximity among some of Maturana's propositions and the Guarani culture.
\end{abstract}

Keywords: Interculture. Indigenous Education. Maturana. Emotion. 